\title{
Vulnerabilidade da família de crianças com estomia intestinal*
}

Vulnerability of families with children with intestinal stomas

Vulnerabilidad de la familia de niños con ostomía intestinal

Clara Ferraz Lazarini Zacarin ${ }^{1}$, Willyane de Andrade Alvarenga ${ }^{2}$,

Renata Olzon Dionysio de Souza ${ }^{3}$, Daianne Cibele de Souza Borges ${ }^{4}$, Giselle Dupas ${ }^{5}$

\footnotetext{
* Este estudo foi apresentado no $V$ Congresso Brasileiro de Enfermagem Pediátrica e Neonatal.

${ }^{1}$ Enfermeira, Mestre em Enfermagem. São Carlos, SP, Brasil. E-mail: clara.lazarini@gmail.com.

2 Enfermeira, Mestre em Enfermagem. Discente do Programa de Pós-Graduação em Enfermagem em Saúde Pública, nível Doutorado, da Escola de

Enfermagem de Ribeirão Preto da Universidade de São Paulo. São Carlos, SP, Brasil. E-mail: willyalvarenga@hotmail.com.

${ }^{3}$ Enfermeira. Enfermeira do Hospital Escola Municipal de São Carlos. São Carlos, SP, Brasil. E-mail: rolzon@gmail.com.

${ }^{4}$ Enfermeira. Discente do Programa de Pós-Graduação em Enfermagem, nível Mestrado, do Departamento de Enfermagem da Universidade Federal de São

Carlos (UFSCar). São Carlos, SP, Brasil. E-mail: daiannesouza@yahoo.com.br.

${ }^{5}$ Enfermeira, Doutora em Enfermagem. Professora Associada do Departamento de Enfermagem da UFSCar. São Carlos, SP, Brasil. E-mail: gdupas@ufscar.br.
}

\section{RESUMO}

Estomas intestinais provocam transformações no corpo e geram necessidades de cuidados específicos e contínuos que implicam em internações hospitalares e cirurgias. Nesse contexto, aplicou-se o conceito de vulnerabilidade da família com objetivo de identificar a vulnerabilidade da família que convive com a criança que apresenta estomia intestinal. Trata-se de estudo qualitativo, em que foram entrevistadas mães de crianças com essa condição crônica. Utilizou-se a análise de narrativa subsidiada pelo conceito de vulnerabilidade de família. Os resultados apontaram que as famílias têm experiências anteriores marcantes associadas à condição dos filhos, vivem sozinhas o cuidado das crianças e buscam maneiras de controlar a situação e resgatar sua autonomia, esperando a reversão do estoma. A partir do conceito de vulnerabilidade, percebeu-se que essas famílias podem ser consideradas vulneráveis, pois passam por ameaça em sua autonomia, mas são movidas pela esperança da reversão e reconstrução do trato intestinal da criança. Descritores: Estomas Cirúrgicos; Criança; Família; Enfermagem Pediátrica.

\section{ABSTRACT}

Intestinal stomas cause transformations in the body and create specific and continuous needs for care that imply in hospitalization and surgeries. In this context, we applied the concept of family vulnerability in order to identify the vulnerability of the family living with a child who has intestinal stoma. It is a qualitative study which interviewed the mothers of children with this chronic condition. We used narrative analysis based on the concept of family vulnerability. The results display that the family has gone through previous noteworthy experiences associated with the child's condition. The family cares for the child on their own and seeks ways to control the situation and regain autonomy, hoping for stoma reversal. Based on the concept of vulnerability, we observed that these families can be considered vulnerable, for they experience threats to their autonomy, but are moved by the hope of reversal and intestinal tract reconstruction.

Descriptors: Surgical Stomas; Child; Family; Pediatric Nursing.

\section{RESUMEN}

Los estomas intestinales producen transformaciones corporales necesitan de cuidados específicos y continuos, implicando internaciones hospitalarias y cirugías. En tal contexto, se aplicó el concepto de vulnerabilidad de la familia, objetivando identificar la vulnerabilidad de la familia que convive con el niño con estoma intestinal. Estudio cualitativo en el que fueron entrevistadas madres de niños con dicha condición crónica. Se utilizó el análisis de narrativa con soporte del concepto de vulnerabilidad de familia. Los resultados expresaron que la familia posee experiencias previas determinantes, asociadas a la condición del niño. La familia experimenta en soledad el cuidado del niño y busca maneras de controlar la situación y preservar su autonomía, esperando la reversión del estoma. Respecto al concepto de vulnerabilidad, se percibió que esas familias pueden considerarse vulnerables, ya que sufren una amenaza a su autonomía, pero resultan movilizadas por la esperanza de reversión y reconstrucción del tracto intestinal del niño.

Descriptores: Estomas Quirúrgicos; Niño; Familia; Enfermería Pediátrica. 


\section{INTRODUÇÃO}

Estomia é uma palavra de origem grega que significa abertura por processo cirúrgico. Essa abertura é realizada na superfície cutânea e forma uma comunicação entre o órgão e o meio externo, quando há necessidade de desviar o trânsito normal da alimentação e/ou eliminações. A denominação varia com a região ou órgão (como traqueostomia, gastrostomia, colostomia, íleostomia, urostomias, etc). É realizada no tratamento de alterações congênitas, patológicas ou traumáticas e seu tempo de permanência varia com a doença de base e outros fatores que podem influenciar na reconstrução das áreas modificadas ${ }^{(1-3)}$.

As estomias intestinais provocam limitações e transformações no corpo e em seu funcionamento, gerando necessidades de cuidados específicos e contínuos. Podem afetar as funções do indivíduo em suas atividades diárias, além da possibilidade de hospitalização durante um ou mais meses por ano, por isso são consideradas condições crônicas ${ }^{(1-4)}$.

Em primeiro momento o diagnóstico de doença ou condição crônica deixa a família desamparada e sem controle da situação, não sabendo o que a espera, o que é a doença e qual a real necessidade de intervenções, como cirúrgicas nos casos das estomias. A falta de controle gera sentimentos de negação, medo e angústia e a família necessita ser potencializada como cuidadora e ser auxiliada na aquisição de novas habilidades e no cuidado relativo há higiene, troca de bolsas coletoras, manutenção da integridade cutânea, entre outras ${ }^{(1)}$.

Existem estudos que mostram que os pais de crianças estomizadas passam por grande nível de estresse emocional, e os sentimentos negativos desencadeados por vezes geram conflitos sobre os cuidados do filho ${ }^{(5-6)}$.

Além das transformações no corpo e nas rotinas da família, a realidade de ter uma criança com estomia intestinal implica em passar diversas vezes por internações hospitalares e intervenções cirúrgicas, desde a confecção do estoma, até correções do trato intestinal, incluindo as dilatações anais, anastomoses e outras. Devido a essas circunstâncias, pode-se avaliar a aplicabilidade do conceito de vulnerabilidade da família(7) que em situação de doença de um filho é caracterizada pelo sentimento de ameaça da sua autonomia e pela sensação de pressão da família, da equipe e da doença.

A vulnerabilidade da família é um processo que pode ser desencadeado por experiências vividas anteriormente, pelo acúmulo de demandas que dificulta e compromete a maneira da família lidar com a situação e o despreparo para agir nesta situação. Como consequência, a família alterna momentos em que tem dificuldade para se reerguer e outros em que tenta resgatar sua autonomia. É um movimento dinâmico e contínuo ao longo de toda experiência da doença ${ }^{(6)}$.

Os antecedentes ou experiências vividas anteriormente são elementos determinantes para desencadear vulnerabilidade em uma família que vivencia situação de doença ou hospitalização, uma vez que novas demandas são diferentemente enfrentadas de acordo com cada experiência anterior vivenciada, e o despreparo para agir diante delas pode comprometer a maneira de lidar com situações. Os atributos definidores estão relacionados ao contexto da doença podendo gerar sentimentos diversos como incerteza, impotência, ameaça real ou imaginária, exposição ao dano, temor do resultado, submissão ao desconhecido e expectativa de retornar à vida anterior. Além disso, uma família com desequilíbrio em sua capacidade de funcionamento tende a ficar mais desestruturada, o que gera alteração e conflitos na vida familiar ${ }^{(7)}$.

Como consequência, a família, num processo dinâmico e contínuo, alterna momentos de impotência e outros em que tenta resgatar sua autonomia. Isso atribui uma transitoriedade a seu sentimento de vulnerabilidade ao longo da experiência vivenciada ${ }^{(6)}$.

A partir dos fatores de vulnerabilidade de família, os profissionais de saúde poderão identificar pontos de fragilidades nas famílias e assim lidar melhor com essa situação, de modo a planejar ações e evitar agravos. Este é um tema relevante na enfermagem pediátrica, visto que os avanços nos atendimentos a neonatos prematuros ou com problemas congênitos têm permitido maior sobrevida, porém, muitas vezes, com evolução clínica de dependência de dispositivos tecnológicos ${ }^{(8)}$.

Os conhecimentos relacionados às práticas de enfermagem e a vivência de crianças estomizadas e suas famílias em ambiente domiciliar, ainda são pouco explorados em âmbito nacional, o que torna esse estudo importante para compreender a realidade em que a família vive, como são feitos os cuidados específicos diários para com a criança estomizada e como a família enfrenta essa situação. Assim, esse estudo objetivou caracterizar a existência de vulnerabilidade na família que convive com a criança que possui estomia intestinal, e teve como objetivo específico identificar os elementos desencadeadores, atributos e consequências dessa experiência. 


\section{MÉTODO}

Este é um estudo de abordagem qualitativa que possibilitou compreender significados da experiência através de uma visão subjetiva e interpretativa da realidade; isso porque a pesquisa qualitativa possibilita apreender pensamentos e ações para desenvolver o conhecimento do ponto de vista de quem vivencia uma situação( ${ }^{(9)}$.

Para nortear a pesquisa optou-se por utilizar o conceito de vulnerabilidade da família para identificar os elementos definidores, atributos e consequências, eixos do conceito sob estudo(7). Entende-se que a vulnerabilidade da família ao longo da experiência da doença e hospitalização da criança é um processo dinâmico e contínuo. Este conceito abarca desde os elementos desencadeadores, como as experiências vividas anteriormente, perpassa pelos atributos definidores de que estão relacionados ao contexto da doença e gera incerteza, impotência, ameaça real ou imaginária, exposição ao dano, temor do resultado, submissão ao desconhecido e expectativas de retornar à vida anterior e tem como consequência, a alternância de momentos em que não consegue fazer nada, com outros em que a família tenta resgatar sua autonomia.

Este estudo foi realizado com seis famílias de crianças que possuem estomia intestinal e estão cadastradas em um Centro de Especialidades no interior do estado de São Paulo, onde fazem acompanhamento. Ali as famílias recebem orientações para os cuidados e manuseios dos dispositivos coletores utilizados nesse tipo de estomia (Quadro 1). Essas famílias foram selecionadas a partir do seguinte critério de inclusão:

- ter na família uma criança (de zero a 12 anos) que possui estomia intestinal, independente do tempo, que faz acompanhamento ambulatorial neste serviço e reside na cidade ou na microrregião de atendimento.

A coleta de dados foi realizada de novembro de 2012 a julho de 2013. O serviço de saúde disponibilizou uma lista contendo sete famílias de crianças estomizadas em acompanhamento. Dessas, uma recusou-se a participar do estudo. Em princípio o primeiro contato era realizado no próprio serviço de saúde, após consulta. Quando a família não comparecia à consulta, o contato era realizado via telefone, para posteriormente agendar uma visita domiciliar. Apesar de todos os familiares presente serem convidado à participar, somente as mães se dispuseram a contar sobre a experiência da família.

Para a coleta de dados foi utilizada a entrevista aberta com uma questão norteadora em que era perguntado "como é para a família conviver com a estomia do seu filho, desde o momento em que foi diagnosticada a necessidade de realizar a estomia e quais dificuldades ou facilidades encontradas no dia a dia, além das mudanças na vida familiar". As entrevistas foram realizadas após assinatura do Termo de Consentimento Livre e Esclarecido os depoimentos foram audiogravados.

Essa pesquisa seguiu todos os preceitos éticos e legais com base na Resolução 196/96 do Conselho Nacional de Saúde, em vigor no momento de elaboração e execução do projeto, e teve parecer favorável do Comitê de Ética e Pesquisa da Universidade Federal de São Carlos - UFSCar para sua realização, em 14 de agosto de 2012 com o n 53018.

Após a transcrição na íntegra de cada entrevista, foram realizadas leituras repetidas utilizando o método de análise de narrativa(10-11). Neste processo as falas foram recortadas e agrupadas em três temas principais que correspondiam aos antecedentes, atributos e consequências. Em seguida foi feito nova leitura dos recortes das narrativas e apreendido os pontos em comum. Assim surgiram quatro categorias que serão apresentadas nos resultados.

As falas estão identificadas com a letra $M$ de mãe e os números correspondentes à ordem cronológica da entrevista (ex.: M1 corresponde à primeira mãe entrevistada e M6 à última) e a letra C seguida de número, corresponde à criança da família.

\section{RESULTADOS}

As entrevistadas foram realizadas com seis mães de crianças estomizadas que obedeceram ao critério de seleção. As idades das crianças variaram de sete meses a nove anos, sendo este também o tempo de uso do estoma, já que foram realizados ainda no primeiro mês de vida de cada criança. Dentre as causas para a realização da estomia foram Ânus Imperfurado (duas crianças), Enterocolite Necrosante (três crianças) e Doença de Hirshprung (uma criança) (Quadro 1).

Após a análise das narrativas e tomando por base o conceito de vulnerabilidade da família e os seus eixos (elementos definidores, atributos e consequências) foi possível apreender da experiência da família e identificar as situações de vulnerabilidade que foram categorizadas conforme o Quadro 2: 
Quadro 1: Caracterização das crianças com estomias intestinais participantes do estudo. Município do Estado de São Paulo, Brasil, 2013.

\begin{tabular}{|c|c|c|}
\hline Identificação da criança & Tipo de estomia & Enfermidade central \\
\hline Criança 1 - Sexo masc./ 9 anos & Colostomia (9 anos de uso) & $\begin{array}{c}\text { Múltiplas Malformações congênitas (Ânus } \\
\text { imperfurado) }\end{array}$ \\
\hline Criança 2 - Sexo masc./ 4 anos & Colostomia (4 anos de uso) & Ânus imperfurado \\
\hline Criança 3 - Sexo masc./ 7 meses & $\begin{array}{c}\text { Colostomia (7 meses de } \\
\text { uso) }\end{array}$ & Enterocolite Necrosante (Prematuridade Extrema) \\
\hline Criança 4 - Sexo Fem./ 2 anos & Colostomia (2 anos de uso) & Enterocolite Necrosante (Prematuridade Extrema) \\
\hline Criança 5 - Sexo masc./ 7 anos & Íleostomia (7 anos de uso) & Doença de Hirshprung \\
\hline $\begin{array}{c}\text { Criança 6 }- \text { Sexo masc./ } 1 \text { ano } 3 \\
\text { meses }\end{array}$ & Colostomia (1 ano de uso) & Enterocolite Necrosante (Prematuridade Extrema) \\
\hline
\end{tabular}

Quadro 2: Categorização oriunda da experiência da família de crianças com estomias intestinais, segundo o conceito de vulnerabilidade para a família. Município do Estado de São Paulo, Brasil, 2013.

\begin{tabular}{|c|c|}
\hline \multicolumn{2}{|c|}{ Experiência da família } \\
\hline Elementos Definidores & Categorias \\
\hline Atributos & 1. Ter experiências marcantes associadas à estomia \\
\hline \multirow{2}{*}{ Consequência } & 2. Viver sozinho o cuidado da criança com colostomia \\
\cline { 2 - 2 } & 3. Buscar o controle da situação \\
\hline
\end{tabular}

\section{Ter experiências marcantes associadas à estomia}

A experiência de ter um filho com uma estomia intestinal traz consigo longos e vários períodos de hospitalização, cirurgias e procedimentos antes e depois da confecção do estoma. A família vivencia diversas experiências negativas e inúmeros procedimentos dolorosos que geram sofrimentos. A família demonstra no inicio dificuldade em enfrentar as situações inesperadas e algumas complicações durante o processo de hospitalização são marcantes.

O C1 nasceu assim, com lábio leporino, fenda palatina, espinha bífida, sem o esôfago e com imperfuração do ânus. [...] fizeram a cirurgia do lábio, a reconstrução do palato e agora [com 8 anos], fez a correção do esôfago e vai fazer a do intestino, a da imperfuração do ânus. (M1)

A vivência de hospitalização e cirurgias gera na família grande sofrimento, medo e impotência, pois mesmo ciente da necessidade do procedimento (cirurgias, punções etc.) para sobrevivência, não quer vê-la sofrer. A família passa muito tempo dentro do hospital e se afasta de atividades rotineiras, como emprego e escola, o que provoca grande desgaste.

Ele marcava a cirurgia e abria o canal, ai voltava para casa, passavam uns dias fechava de novo. Quando marcava para fechar a colostomia, chegava lá o canal tava fechado, ai abria de novo. Ele fez bastante cirurgia para abrir o canal, ao todo foram 11 cirurgias. (M2)

\section{Viver sozinho o cuidado da criança com colostomia}

A família, na perspectiva da mãe, se sente sem o controle da situação, pois a doença altera seu modo de vida. É clara a sobrecarga materna no papel de cuidador principal da criança. Em alguns casos são relatadas ajudas de outro familiar, porém ninguém assume o cuidado integral junto com a mãe, que organiza seu dia a dia em função dos cuidados da criança e se vê sem apoio da sociedade, dos demais familiares e percebe $o$ preconceito dos profissionais na escola que afastam a criança da convivência com os demais, deixando-a em situação humilhante.

Eu aprendi tudo sozinha. Assim, de falar que alguém ensinou como deve fazer isso não. Eu aprendi sozinha. Tive que aprender. (M1)

Na escola, para esvaziar a bolsa, ninguém colocava a mão, então era o jardineiro que levava ele no posto de saúde pertinho, e levava ele com chuva ou frio. Então, já que tinha que ser assim, levasse umas três vezes no dia, ele ficava o dia todo [na escola]. Levavam uma vez, como não dava tempo, vazava. Ele era colocado no último banco da van, lá no fundo porque ninguém aguentava o cheiro. Então foi assim, ele passou por muito constrangimento. (M5)

A mãe além de se sentir responsável em proteger o filho dos preconceitos, muitas vezes organiza-se em função da condição da criança e faz escolhas para se adaptar à realidade. Algumas vezes precisa afastar a criança da escola pela falta de apoio da instituição e com isso a mãe deixa o emprego para cuidar do filho. 
Ele passou um mês e pouco na escolinha e eu estava no serviço, em experiência. A diretora [da escola] ligava direto, todos os dias ela ligava, e lá [serviço] não podia atender telefone. Até que eu saí, pedi demissão do serviço e já fui buscar ele. Não deixei mais um dia na escolinha. Porque quando ele fica na escolinha e eu fico para cima e para baixo indo buscar, então melhor ficar em casa. (M2)

O desamparo também é vivido no contexto hospitalar, quando a criança está internada, principalmente no que diz respeito à comunicação com a equipe de saúde. Muitas vezes a equipe não se preocupa com a forma de transmitir as notícias, desrespeitando o sentimento da família, que se sente agredida, quando na verdade gostaria de ser acolhida.

Mas eu falei que os médicos tinham que ter jeito para conversar com a gente, e não falar que "ta grave, faltam tantos dias para morrer". Ele não é Deus. Porque de repente ele fala "vai morrer amanhã", mas Deus fala "Não chegou a hora dele". (M4)

Na realidade, o médico chegou de "supetão". Ele deixou bem claro que não sabia o que fazer. Então foi um clima terrível. Porque o combinado era melhorar a ileostomia, retirar a hérnia e isolar a parte de baixo [região anal] porque ele ainda usa fralda e não foi feito nada disso. (M5)

\section{Buscar o controle da situação}

A vivência com a estomia promove na criança e em sua família manejos de adaptação ao modo de vida. Muitas vezes, para amenizar o impacto do uso do dispositivo a família se apega ao fato de que a criança sobreviveu a uma cirurgia e está bem e fica fortalecida com isso. Sentimentos de medo também perpassam essa experiência, seja nos momentos críticos da hospitalização ou nos cuidados domiciliares, tentando sempre resgatar o controle da situação.

Eu pensava que aquele "negócinho" dela [estomia] ia sair e eu pensava: Meu Deus o que vou fazer? Sozinha para ter que cuidar? Eu colocava ela na cama, tirava a fralda, lavava primeiro a mão, passava o produto na mão, e limpava. Na Unidade de Terapia Intensiva, me ensinaram. Ai quando ela fazia as necessidades dela eu limpava e eu fui acostumando. Mas em casa eu ficava com medo de pegar alguma bactéria, de ela se machucar. (M4)
A família procura acompanhar de perto e aprender a lidar com o novo. Demonstra força por meio da espiritualidade, para afastar o medo, deixando transparecer a fé em que se sentem amparadas e com mais esperança para lutar.

Ele nasceu de 25 semanas e 3 dias. Para mim logo no começo foi difícil, foi com base na oração mesmo, para estar fortalecendo a gente, porque não foi fácil. Quando ele estava melhorando, rompeu o intestino dele e a gente não tinha o que fazer. Se tem que fazer a cirurgia então vamos fazer. Ai eu falei: Está na mão de Deus. O que a gente pode fazer aqui é orar e se apegar bastante com Deus porque a gente não pode fazer nada. Só de ele estar vivo já é uma benção. (M3)

\section{Esperar pela possibilidade de reversão da estomia}

A reversão da estomia para a família denota a retomada de controle sobre a situação. A expectativa em retomar a vida anterior ronda a família o tempo todo, porém é permeada pelo medo da mudança, já que a criança encontra-se estável e a família já passou pela fase crítica de adaptação à colostomia. A vulnerabilidade se faz presente neste contexto em que as experiências anteriores fazem com que o real e o imaginário se misturem, e medo de perder a criança fica reforçado, o que torna duvidoso o desejo da correção do trânsito intestinal. É uma fase em que há espera e ansiedade.

Estou com medo de ela ir e não voltar. Eu fico pensando como vai ser, porque a gente já acostumou com ela aqui, que ela já anda, então a gente fica com medo. Eu espero que ela coloque para dentro [reversão] e que ela fique bem. Tenho medo de ela fazer a cirurgia e tenho medo depois que ela sai dali. [pausa- choro]. Acho que se acontecer alguma coisa com ela acontece comigo também. (M4)

Ele vai ter que refazer a cirurgia e a gente fica com um pouco de medo, porque é cirurgia. Só de ele estar vivo, é o que importa, entendeu? É assim, ele esta com colostomia, tem que ter os cuidados, mas enfim, está vivo. Então o mais importante é isso. (M3)

\section{DISCUSSÃo}

A hospitalização é vivenciada como um período crítico e difícil em que frequentemente a família demonstra sentimento de culpa, raiva e choque pela necessidade de realização da cirurgia em seu filho, que na maioria das vezes é feita durante operações de emergência, horas ou dias após o nascimento do bebê, o 
que leva a separação precoce da criança de sua mãe e família.

A vulnerabilidade utilizada como referencial fica evidenciada durante a trajetória enfrentada por essas famílias que é permeada por três fases marcantes, sendo, no primeiro momento caracterizado pela desestruturação familiar que vem com a notícia da condição frágil e inesperada que o filho se encontra. Em seguida ocorre a fase de reorganização que acontece após o diagnóstico, em que se deparam com a realidade de cuidar do estoma e por fim a fase de enfrentamento em que aprendem a lidar com o estoma, mas aparecem as dificuldades na inserção social dessa criança, principalmente na escola(13).

Observou-se nesse contexto que o cuidador principal da criança que tem estoma intestinal é a mãe, que muitas vezes se vê sozinha. Desde a fase de hospitalização até nos cuidados em casa ela permanece responsável por fazer o elo entre a criança, família e sociedade, recaindo-a todas as responsabilidades referentes a esta situação em particular. Isso acontece provavelmente por questões culturais e sociais em que as mulheres agregam características de cuidadoras e atuam de forma decisiva no cuidado à criança ${ }^{(6)}$.

Após a cirurgia para a realização do estoma, em decorrência da modificação do local fisiológico de evacuação, é comum relatos de dificuldades nos primeiros cuidados com seu filho, evidenciando medo de segurar a criança e insegurança para proceder adequada higiene ao redor do estoma. Além disso, a visualização do estoma na região abdominal é algo que em primeiro momento impressiona e nem todos os familiares se sentem confortáveis em ver ou ter contato com o mesmo. Nesta fase fica claro o conceito do primeiro eixo da vulnerabilidade pois a família ao vivenciar essa experiência sente-se ameaçada em sua autonomia. A imposição de ter que viver com uma realidade da qual não se tem controle deixa a família enfraquecida e "à mercê da situação". Nesse contexto a família precisa adquirir novas competências e habilidades que não faziam parte do seu cotidiano até aquele momento ${ }^{(6-14)}$.

A realização de um estoma intestinal é um procedimento relativamente frequente no mundo da cirurgia pediátrica, porém apesar dos benefícios imediatos de salvar a vida, a condição de possuir um estoma pode trazer complicações e morbidades que aparecem ao longo do tempo, que podem impedir ou tardar a reversão ${ }^{(15)}$. Muitas crianças que são submetidas a esse tipo de cirurgia passam por complicações e necessitam de outros procedimentos, inclusive novas cirurgias, o que deixa a família mais vulnerável por não saber o que vem pela frente, apesar disso, são impulsionados a desencadear maneiras de equilibrar a esperança e o medo frente ao novo cotidiano familiar ${ }^{(6-}$ 16).

O convívio social dessa criança também fica comprometido, porque enfrentam situações constrangedoras, como vazamento do conteúdo fecal, odores e principalmente pelo desconhecimento de outras pessoas sobre assuntos relacionados aos cuidados. A presença do estoma exige cuidado e a presença da incontinência pode tornar difícil a socialização. Assim, muitas vezes ocorre uma espécie de confinamento domiciliar feito pela própria família, mesmo sabendo que a presença do estoma não impede a criança do convívio social ${ }^{(6)}$.

O preconceito é uma realidade vivenciada por quase todas as famílias e a relação indivíduo-sociedade é limitada e traz muito sofrimento. Assim como em outras situações de cronicidade na infância, a presença da estomia também está relacionada a uma condição anormal, e isso está agregado com características negativas, constrangedoras e limitantes, que podem inclusive provocar alterações no desenvolvimento desta criança que sofre a exclusão(17).

Por esse e outros motivos, a consequência é evidenciada na fase de busca pela reversão e reconstrução do trato intestinal que muitas vezes se torna objetivo principal da família. Apesar de passar pelo processo de adaptação a esperança pela reversão e a retomada do controle é almejada para enfim levar uma vida "normal". A condição de ter um estoma temporário causa ansiedade em todos que convivem com a criança, além disso, a reconstrução do trato intestinal nem sempre é bem sucedida logo na primeira tentativa e isso pode levar à descrença e ao medo de dar errado algo que foi tão desejado e planejado. Sabe-se que a criança que nasce com alguma malformação anorretal precisa de avaliações cuidadosas e a reconstrução da área afetada deve ser feita com precisão e cautela para que minimize a ocorrência de problemas que possam comprometer a qualidade de vida futura ${ }^{(6-18)}$.

É fundamental que existam apoio e acompanhamento de profissionais de saúde em todo o processo de vivência, desde o inicio do diagnóstico, para que facilite $o$ aprendizado em lidar com as transformações decorrentes da estomia e incentive os cuidados precoces, assim que a condição da criança permitir e ainda no ambiente hospitalar, começando com as tarefas mais simples, como esvaziar ou trocar a 
bolsa ${ }^{(13)}$. Para isso os profissionais precisam estar capacitados para ampará-los no que tange às transformações decorrentes da estomia, já que a criança fica propensa a enfrentar diversas modificações ${ }^{(5)}$.

Os cuidados e orientações devem ser focados em todos os membros da família, com o objetivo de estabelecer vínculo, criar elo de confiança e segurança que ajuda a desenvolver a autonomia do grupo familiar para melhor enfrentamento das dificuldades da terapêutica clínica e para um crescimento mais saudável da criança. A equipe de saúde precisa estar capacitada e possuir habilidades educativas para ajudar os familiares no cuidado da criança e no manuseio dos dispositivos tecnológicos ${ }^{(6-18)}$.

\section{CONCLUSÃO}

Com a realização deste estudo foi possível compreender a experiência vivida por essas famílias, a partir do conceito de vulnerabilidade para a família.

Os resultados apontam que o objetivo foi contemplado, visto que foi possível identificar que a família que convive com a criança estomizada pode ser considerada vulnerável, uma vez que nesse contexto passam por diversas demandas inesperadas e seus enfrentamentos variam com as experiências anteriores que cada um dos membros vivenciou com relação à estomia. A família perpassa um processo dinâmico e contínuo que ameaça sua autonomia, mas com o tempo percebe que essa convivência é administrável e passível de adaptações no cotidiano, sendo possível pensar e planejar um futuro para a criança principalmente porque a estomia intestinal na infância é frequentemente revertida.

Apesar do medo de novos procedimentos e internações a expectativa da reversão ronda a família o tempo todo e gera esperança de ter de volta a criança que foi desejada antes de nascer. Essa é uma fase de ansiedade e espera que move a família para a possibilidade futura de retomar sua vida como havia planejado antes da chegada do filho.

Como fator limitante apontamos a entrevista realizada somente com a mãe das crianças estomizadas o que possibilitou compreender somente um olhar sobre a experiência que acerca a família neste contexto. Sendo assim abre-se a possibilidade de realizar novos estudos com outros membros familiares e inclusive com a criança para ampliar o conhecimento sobre essa experiência.

Com este trabalho acreditamos ter contribuído para o conhecimento na área, pois a estomia em criança é um assunto ainda pouco explorado na área da enfermagem, principalmente no contexto familiar. Com os resultados podemos concluir que ao identificar a vulnerabilidade dessas famílias os profissionais de saúde podem desenvolver olhar apurado e maior sensibilidade para atender essas crianças e suas famílias e assim minimizar efeitos negativos que essa experiência pode desencadear em seus membros.

9. Lacerda MR, Lambronici LM. Papel social e paradigmas da pesquisa qualitativa de enfermagem. Rev. Bras Enferm. 2011; 64(2):359-364.

10. Silva DGV, Trentini M. Narrativas como técnicas de pesquisa em enfermagem. Rev. Latino-am enferm. USP. 2002; 10(3):42332.

11. Ordaz, I. O Uso das Narrativas como Fonte de Conhecimento em Enfermagem. Rev. Pensar Enfermagem. Lisboa. 2011; 15(1):70-87.

12. Coldicutt $P$, Hill B. An overview of surgical stoma construction and its effects on the child and their family. Nursing children and young people. $2013 ; 25(4): 26-35$.

13. Neves ET, Cabral IE. Cuidar de crianças com necessidades especiais de saúde: desafios para as famílias e enfermagem pediátrica. Rev. Eletr. Enf. [Internet]. 2009 [acesso em: 17 de Julho de 2013]; 11(3):527-38. Disponível em: http://www.fen.ufg.br/fen_revista/v11/n3/sumario.htm.

14. Bischoff A, Levitt MA, Lawal TA et al. Colostomy closure: how to avoid complications. Pediatr Surg Int. 2010; 26:1087-1092. 15. Struijs MC, Sloots CE, Hop WC et al. The timing of ostomy closure in infants with necrotizing enterocolitis: a systematic review. Pediatr Surg Int. 2012; 28:667-72.

16. Simões CC, Silva L, Santos MR et al. A experiência dos pais no cuidado dos filhos com paralisia cerebral. Rev. Eletr. Enf. [Internet]. 2013 [acesso em: 17 de Julho de 2013]; 15(1):1384. Disponível em: http://www.fen.ufg.br/fen_revista/v15/n1/v15n1.htm. 
17. Souza PCM, Costa VRM, Maruyama SAT, Costa ALRC,

Rodrigues AEC, Navarro JP. As repercussões de viver com uma colostomia temporária nos corpos: individual, social, e político. Rev. Eletr. Enf. [Internet]. 2011 [acesso em: 17 de Julho de 2013]; 13(1):50-9. Disponível em:

http://www.fen.ufg.br/fen_revista/v13/n1/v13n1.htm.

18. Gilbert MJ, Mello DF, Lima RAG. Experiências de mães de filhos com doença de hirschsprung: subsídios para o cuidado de enfermagem. Esc Anna Nery Rev Enferm. UFRJ. 2009;

13(4):793-801.

Artigo recebido em 30/09/2013.

Aprovado para publicação em 07/02/2014.

Artigo publicado em 30/06/2014. 